\title{
Nuevas formas de moralidad en los y las jóvenes chilenos Estudio exploratorio sobre configuraciones valóricas emergentes en jóvenes estudiantes de Santiago
}

\author{
Tomás Marín Troncoso ${ }^{1}$
}

\begin{abstract}
Resumen
La desnormativización de la vida social en la época contemporánea está dejando a nuestras juventudes con un problema de crisis de sentido. El repliegue de las instituciones tradicionales que otorgaban significación implica una progresiva individualización de los proyectos de vida, que se manifiesta como un sentimiento de permanente búsqueda. Las juventudes viven en una situación de "intemperie moral", en donde ya nadie les garantiza que sus comportamientos estén en lo correcto en un sentido claro y único. Frente a ello, una solución posible corresponde a la emergencia de una configuración valórica en torno a la noción de autocuidado. Esta involucra la formación de una cautela reflexiva, que permite la protección de la propia subjetividad en un mundo donde las normas están relativizadas, evitando consecuencias no deseadas y sorteando, provisoriamente, el problema de la demanda por sentido.

Para analizar adecuadamente este fenómeno, se recurrió a una estrategia metodológica cualitativa, a partir de la técnica del grupo de discusión. Cabe señalar, por último, que el presente artículo fue realizado en el marco de una tesis de pregrado becada por el proyecto FONDECYT $\mathrm{N}^{\mathrm{o}}$ 1070105: "Cultura juvenil y producción valórica en estudiantes de educación secundaria y de educación superior".
\end{abstract}

Palabras clave: Crisis Normativa, Proyecto De Vida, Autocuidado

\begin{abstract}
The tendency to having a lack of regulations of social life in contemporary times is leaving our young people with a problem of sense crisis. The retreat of the traditional institutions that gave meaning implies a progressive individualization of life projects, which is shown as a feeling of permanent search. Youngsters live in a situation of "moral neglect", where nobody is able to guarantee that their behavior is correct in a clear and unique sense. In this respect, a possible solution corresponds to the emergence of a value configuration around the notion of selfcare. This involves the formation of a cautious reflection, which allows the protection of their own subjectivity in a world where the rules are
\end{abstract}

1 Sociólogo, Universidad de Chile. E-Mail: tmarint@gmail.com 
Nuevas Formas de Moralidda en los y las Jóvenes chilenos. Estudio exploratorio sobre configuraciones valóricas emergentes en jóvenes estudiantes de Santiago

relativized, avoiding unintended consequences and to avoid, temporarily, the problem of demand of meaning.

To properly analyze this phenomenon, a qualitative methodological strategy was used, based on the group discussion technique. It should be noticed, finally, that this article was conducted as part of an undergraduate thesis scholarship from the FONDECYT project No. 1070105: "Youth culture and values production in students of secondary and higher education." 


\section{Introducción}

Nuestra sociedad hoy se encuentra transformada. Hay una percepción mayoritaria, tanto en el mundo académico como en la opinión pública en general, de que el tipo de sociedad en que vivimos actualmente no es el mismo de hace unas décadas. Sin embargo, no se trataría tan solo del proceso natural de desarrollo y cambio social que caracteriza a cualquier comunidad, sino que parece evidente que se trata de una transformación mucho más fundamental: la idea de un cambio epocal, entendido como la reformulación general del modelo de modernidad instalado durante los últimos dos siglos.

¿Cómo se manifiesta esto en la vida cotidiana? Los modelos societales concretos que tienen por referencia dicha modernidad occidental, implican, para el sujeto, mundos fundados sobre las instituciones. Es decir, que hay una correspondencia entre personalidad, estructura social y cultura (Garretón, 2000). Y también existe una confluencia entre cada ética con su moral, esto es, principios éticos claros que se expresan en las normas de conducta que llamamos moral. Hay una correspondencia entre valores, normas y conducta, lo que le otorga a cada individuo la posibilidad de encontrar claramente el sentido de su existencia. Esto es lo que en la sociedad actual ya no aparece como evidente y más bien comienza a ser reemplazado por principios éticos emergentes, que aún no tienen instituciones que los expresen. La instalación progresiva del pluralismo, característica de los tiempos que vivimos, va instalando cada vez más dificultades para que el sujeto estructure su vida en torno a determinados valores de significación última, "reservas de sentido", que estén exentos de cuestionamientos.

Esto trae como consecuencia una permanente posibilidad de crisis subjetivas o intersubjetivas de sentido, al no existir valores compartidos que permitan determinar la acción correcta en los diversos ámbitos de la vida. Esto puede entenderse como la relativización de los sistemas de valores y los esquemas de in- 
Nuevas Formas de Moralidda en los y las Jóvenes chilenos. Estudio exploratorio sobre configuraciones valóricas emergentes en jóvenes estudiantes de Santiago

terpretación. Cada aspecto del mundo en general y de la vida en particular queda sujeto a múltiples interpretaciones y esquemas de acción. El "fin de las certezas" (Berger y Luckmann, 1996) corresponde al repliegue de las reservas de sentido que permiten encaminar los proyectos biográficos en torno a determinados valores orientadores que le otorguen significación.

En nuestro país, el impulso de la modernización en las últimas décadas, así como los efectos de los procesos de globalización, van dando lugar a problemáticas de este mismo tipo. Con el retorno a la democracia, han ido perdiendo relevancia las viejas representaciones político-ideológicas en la conformación del proyecto de vida. Atrás quedan las motivaciones de carácter colectivo -el sentido comunitario- para dar lugar a crecientes procesos de individualización. Esto significa que las decisiones acerca de la vida están siendo cada vez más sustentadas en valores eminentemente personales, fenómeno que aparece con especial fuerza en las nuevas generaciones.

En este sentido, puede establecerse una doble relación entre el modelo sociocultural chileno y nuestras juventudes. Las transformaciones culturales del país determinan nuevas configuraciones o sustratos valóricos en las prácticas juveniles, al mismo tiempo que estas acciones van decantando en la posible emergencia de un nuevo modelo sociocultural.

No obstante, aun cuando los valores y símbolos con que se orientaba tradicionalmente la vida se hacen cada vez más difusos, tampoco se instala con propiedad una nueva orientación valórica compartida. Los y las jóvenes de hoy tienen una débil identificación con la política y también con la religión, pero todavía no aparecen nuevos referentes que contribuyan al otorgamiento de sentido en el curso de sus vidas.

Las juventudes se ven, así, obligadas a enfrentar el problema de la incertidumbre llevando a cabo sus construcciones autobiográficas a partir de convicciones propias, con materiales dispersos y cooperaciones muchas veces inestables. 
Este estudio se levanta, entonces, como un intento de ir comprendiendo la manera en que los mundos juveniles están dando solución al problema de la crisis normativa, esto es, a la incapacidad de un modelo de sociedad histórica de establecer normas morales claras, que se correspondan con principios éticos determinados. La pregunta que nos guía es por las particulares configuraciones de valores que van delimitando un sentido en el accionar juvenil, y cuáles son los ámbitos donde el problema de una moral fragmentada se manifiesta con mayor fuerza para ellas y ellos.

La importancia de poder estudiar este segmento de la población es que en los y las jóvenes yace el cambio. Desde ellos y ellas es posible vislumbrar, con mayor claridad, los caminos posibles que recorrerá la sociedad en la (potencial) institucionalización de un nuevo modelo sociocultural.

\section{Antecedentes}

\section{Transformaciones del modelo sociocultural chileno}

Durante los últimos veinte años, aproximadamente, nuestro país ha pasado por una serie de importantes transformaciones, que dan lugar a una sociedad muy distinta a la que existía hasta la década de los ' 80 . Por un lado, se ha logrado una reducción significativa de los niveles de pobreza, acompañada de un aumento en las posibilidades de consumo de los chilenos, así como también de una cobertura creciente del sistema educativo, que nos coloca entre los países con mejores estándares de Latinoamérica. Sin embargo, la desigualdad en la distribución del ingreso sigue siendo el mayor desafío para nuestra sociedad.

Estos procesos van acompañados de importantes transformaciones culturales y valóricas. Se ha producido una creciente igualación de oportunidades y posibilidades en materia de género, y también se van dando mayores niveles de tolerancia y no discriminación, lo que nos habla de una sociedad crecientemente 
Nuevas Formas de Moralidda en los y las Jóvenes chilenos. Estudio exploratorio sobre configuraciones valóricas emergentes en jóvenes estudiantes de Santiago

abierta a la aceptación del pluralismo (ver encuestas Tolerancia y No Discriminación, años 2000 y 2003). Por otro lado, y relacionado a lo anterior, hay mayor apertura, tanto subjetiva como cultural, a los fenómenos de la globalización, manifestada en más aceptación de lo extranjero, pero también en dificultades para la conformación de una identidad nacional (Informe PNUD 2002). Además, existe mayor acceso e injerencia de los medios de comunicación masivos en la población, así como un aumento del consumo cultural.

Otro cambio importante lo constituye la creciente pérdida de importancia de las representaciones político-ideológicas o una desideologización de los proyectos de vida. La esfera política se va haciendo un referente cada vez más débil en la conformación de la subjetividad. Esto significa un progresivo aumento del individualismo, en tanto pierden importancia las motivaciones de carácter colectivo. Hoy en día, las decisiones sobre la vida van siendo determinadas crecientemente por valores eminentemente individuales, sobre lo cual tiene bastante relevancia la progresiva renovación generacional. Así lo señala el Segundo Informe Nacional de Juventud: "existe contundente evidencia que muestra que las personas están progresivamente valorando más el tomar decisiones respecto a su vida en función de valores personales, por sobre el respeto a normas sociales pretéritas o tradicionales, fenómeno que parece más claro en los y las jóvenes" (INJUV, 2006: 81).

Las transformaciones culturales mencionadas van tensionando la estructura valórica, haciéndola más diversa, es decir, dando lugar a la coexistencia de sectores con desigual aceptación de los cambios. Por otro lado, tal como dio cuenta el Informe PNUD 1998, al debilitarse los lazos sociales se produce un aumento de la sensación de inseguridad e incertidumbre en la población. Los espacios de sociabilidad y asociatividad experimentan significativos cambios, al tiempo que el sujeto se desvincula crecientemente de la esfera pública. Así, los ámbitos de integración social 
se van trasladando hoy básicamente hacia el consumo y las comunicaciones.

Como hemos señalado, el agotamiento de un determinado modelo de racionalidad da lugar a la proliferación de nuevos paradigmas, que obligan a repensar las prácticas sociales y los supuestos que subyacían en nuestra comprensión de los fenómenos colectivos. En este sentido, aparecen nuevas dimensiones valóricas en un contexto sociocultural complejo y globalizado, que tiene importantes consecuencias en ámbitos como la educación, trabajo, ocio, religión, sexualidad y política, que definen nuevos estilos de vida.

\section{2. ¿Y las juventudes?}

¿En qué sector de la sociedad se hacen más patentes las transformaciones que venimos mencionando? Evidentemente en las nuevas generaciones, en tanto en ellas se generan rasgos contradictorios y paradójicas que no son comprendidos en el tradicional código del mundo institucional y adulto. Las acciones juveniles se llevan a cabo de una forma particular, que por lo general no responde a las expectativas del resto de la sociedad.

En los y las jóvenes aparecen nuevos espacios éticos de dominio que escapan a la teoría valórica tradicional, lo que hace imperiosa la búsqueda de nuevos supuestos que den cuenta de la relación entre "ser" y "deber ser".

El alejamiento juvenil de la esfera pública y su menor involucramiento en lo colectivo implican que en los y las jóvenes se dé con más fuerza el proceso de construcción de los proyectos de vida desde referentes personales, y, por lo tanto, son los que más necesitan el apoyo cultural de la sociedad para lograr dicha tarea con éxito.

Tanto su débil identificación con la política como su gradual alejamiento de la religión, nos hablan de unas juventudes a las que no les bastan los tradicionales elementos de integración 
Nuevas Formas de Moralidda en los y las Jóvenes chilenos. Estudio exploratorio sobre configuraciones valóricas emergentes en jóvenes estudiantes de Santiago

social. El problema es que aún no emergen claramente nuevas vinculaciones que contribuyan a mantener la cohesión social. Sin embargo, en los y las jóvenes existe menos temor frente a las incertidumbres generadas por esta sociedad en veloz transformación. Ellos y ellas llevan a cabo su autoconstrucción biográfica a partir de sus propias convicciones. Es decir, en contraposición a una pertenencia propiamente comunitaria o una cooperación cívica, en las juventudes tienen lugar fenómenos de construcción de proyectos de vida autorreferidos, y en algunos casos, hasta defensivos (PNUD-INJUV, 2003).

La importancia que tienen las transformaciones al interior del mundo juvenil, es que son un reflejo de los cambios ocurridos en la cultura contemporánea, la cultura global emergente y las nuevas corrientes culturales en una sociedad en transición epocal (Parker, 2000), pero también los y las jóvenes son los sujetos portadores de este cambio, por lo que las maneras como se representan e interpretan el mundo necesariamente determinarán el devenir de nuestras sociedades y darán lugar, seguramente, a estructuras de larga duración en la historia de Chile.

Tal como plantea la investigación conjunta del PNUD-INJUV, "en el mundo de hoy es prácticamente imposible pensar en la existencia de una juventud sin individualización" (2003: 39). Frente al repliegue de las macro-reservas de sentido, el mundo exige que sea uno mismo quien organice su biografía. La individualización, en este sentido, implica una cierta emancipación en la definición de sí mismo.

En la juventud contemporánea se produce una revaloración del ámbito privado y sus espacios de sociabilidad (familia, amigos, pareja), que pasan a funcionar como redes de apoyo. También observamos una tendencia a la individuación en la relación con los espacios de asociatividad. Las expresiones asociativas juveniles ya no tienen necesariamente connotaciones sociopolíticas ni son el reflejo directo de intereses sociales, sino que son más bien reflejo de la diversidad de corrientes culturales recibi- 
das por los y las jóvenes según sus particulares inclinaciones y vocaciones.

Nos encontramos entonces con que la construcción de las biografías e identidades se lleva a cabo de forma autónoma en las y los jóvenes, a partir de una desinstitucionalización de sus prácticas sociales, un volcamiento hacia la esfera privada y un asociacionismo ligado al interés personal.

\section{Una vida social sin normas}

Durante la dictadura se vivió el predominio de una sola perspectiva ética, lo que mantenía invisibilizado el problema de la incertidumbre, pero con el advenimiento de la democracia y el proceso de transición se hizo patente el conflicto para la consolidación de una "ciudadanía moral", dada la dificultad del sujeto para asumir esta nueva autonomía (Villela et al., 1998).

En la actualidad, aparecen nuevas orientaciones culturales, que dan cuenta del problema de una crisis normativa. Lo que las caracteriza es la hibridación de configuraciones inestables de valores, normas, actitudes, opiniones y comportamientos: se combinan pautas de distintos modelos de acción, tanto individual como colectiva.

El problema entonces es la pregunta por los valores determinantes en el modelo de sociedad vigente, es decir, aquellos que fijan una propensión hacia ciertas orientaciones y comportamientos. La respuesta es, como hemos estado señalando, que éstos se han diversificado. Lo que así aparece como rasgo principal en la orientación cultural chilena "es una fusión contradictoria entre estas diversas orientaciones valóricas como forma a la vez de adaptarse y de protegerse contra el avasallamiento del mercado, las comunicaciones y los poderes fácticos" (Garretón, Op. Cit: 179).

Volviendo ahora al dilema moral, señalaremos que el problema actual de la relación entre la ética y la moral puede entenderse como una "desinstitucionalización de la vida social", esto es, el 
Nuevas Formas de Moralidda en los y las Jóvenes chilenos. Estudio exploratorio sobre configuraciones valóricas emergentes en jóvenes estudiantes de Santiago

debilitamiento de los sistemas normativos y evaluativos que permiten fijar un marco general para la vida comunitaria. La presencia de un orden social ordenado desde las lógicas del consumo y la comunicación, pero que a la vez mantiene sus referentes políticos y económicos, va generando "procesos profundos de desnormativización de la sociedad, que apuntan al problema futuro de la renormativización, donde ética y moral rompen su coherencia y seguridad, y donde los principios que constituyen instituciones, dejan de ser expresados por éstas" (Ibid.: 38). Esto va generando mayores niveles de incertidumbre y, por ende, la búsqueda, por parte del sujeto, de ciertos parámetros que le permitan controlar esta situación. Ocurre, entonces, que dichos parámetros comienzan a surgir desde el mundo privado. La sociedad chilena contemporánea, para Garretón, se caracteriza por la carencia de parámetros únicos y homogéneos que rijan los comportamientos. Con ello, la experiencia de vida se va refiriendo crecientemente al sujeto, en desmedro de un principio o una norma.

La principal manifestación de la desnormativización social o crisis normativa, la constituye la ruptura entre ética y moral. Entenderemos la primera como el principio de la realización humana, su visión de lo bueno. Ésta no dice qué se debe hacer, sino aquello que le sirve de fundamento: los principios éticos; y la segunda, como el conjunto de normas (código normativo) que permite realizar lo que es tenido por bueno o correcto, a partir de determinadas formas de pensar y actuar. Desde ella es posible defender lo que se entiende como valor.

Por mucho tiempo, la ética y moral estuvieron en concordancia, es decir, siempre coexistieron distintas éticas y distintas morales, pero entre ellas se correspondían. Hoy ya no es así. Estamos en una sociedad que cuenta con ciertos principios éticos, pero que no se materializan en instituciones o normas morales claras.

Ahora, la ética también se va transformando. Aparecen nuevas formas éticas referidas a la intersubjetividad, es decir, que no 
se basan en un determinado valor o norma, sino en un principio intersubjetivo que pasa a ser ético: la felicidad. Desde un plano psicosocial, diremos que la felicidad alude a la realización personal. Es desde ahí que hoy se van dictando cada vez más los comportamientos, en tanto la autorrealización se va superponiendo a la norma y la convención social, y también a principios o valores basados en lo que se considera bueno por tradición.

El principio de la felicidad o autorrealización se construye desde las particulares experiencias de vida. Sin embargo, esto conlleva a que no aparezcan como evidentes las normas que aseguran este nuevo principio ético. Pese a imponerse, la ética de la intersubjetividad no tiene instituciones que la aseguren. El de la realización personal es un principio ético que, al construirse intersubjetivamente, tardará bastante en institucionalizarse, pero que, sin embargo, ya está instalado. No es la verdad absoluta lo que prima ahora, sino una marcada búsqueda personal e intersubjetiva.

En el caso de los y las jóvenes, esto se entiende a partir de la instalación del proyecto de vida como un aspecto central para la generación de identidades juveniles. Éste no hay que entenderlo sólo como las particulares metas en la vida, pues tiene mucha importancia también el recorrido a seguir para lograrlas. Ello implica un presente que se vive intensa y profundamente para construir el futuro (Duarte et al., Op. cit.). De esta forma, los y las jóvenes -como sujetos- se van empoderando de su nuevo lugar como actores sociales relevantes, exigiendo ser considerados como personas valiosas y con aportes a entregar. Sin embargo, su renovada posición sociocultural implica también que en ellos sean muy patentes los problemas de la desinstitucionalización de la vida social. Esto se manifiesta en dos ámbitos especialmente relevantes: el carrete y la sexualidad.

El carrete aparece como una de las prácticas más representativas y extendidas en las juventudes chilenas desde los '90, un ámbito transversal de sociabilidad y una de sus prácticas/espa- 
Nuevas Formas de Moralidda en los y las Jóvenes chilenos. Estudio exploratorio sobre configuraciones valóricas emergentes en jóvenes estudiantes de Santiago

cios más valorados. Se constituye como un escenario cultural que atraviesa en general la vivencia de ser joven en Chile (Matus, 2004).

Como espacio ritual, el carrete se construye como lugar de transgresión del orden de la vida cotidiana y puesta entre paréntesis de la norma. Se conforma como un espacio lúdico con códigos no coercitivos, que le dan a los y las jóvenes la posibilidad de aceptarlos o no. Es, además, el lugar donde pueden procesar y elaborar los problemas relacionados con sus propias condiciones de vida. Permite construir significados y vínculos colectivos en un ámbito donde las reglas son establecidas por ellos y ellas, y no por los adultos. Posibilita, así, la reproducción de sus propios mundos de vida.

En este sentido, interesa recalcar al carrete como espacio de importantes aprendizajes sociales, que permiten a las juventudes explorar sus propios límites en torno a sexualidad, consumo de alcohol y drogas, y vínculos intersubjetivos. Es decir, el carrete es experiencia auto-educativa.

Por su parte, la sexualidad juvenil también sufre importantes transformaciones. La prioridad otorgada al desarrollo personal y la conformación de proyectos individuales se expresa en una postergación del establecimiento de una pareja estable, así como en una mayor apertura en el plano sexual. En la actualidad el ideal de pareja se ha transformado, favoreciendo el desarrollo autónomo de los dos implicados. La búsqueda del éxito y la realización de los proyectos de vida se ven poco compatibles con la elección de una pareja estable, y más acorde a una necesidad de mayor experimentación en materia afectiva, lo que tiene como resultado una flexibilización de los vínculos amorosos. Las instituciones e ideologías que se manejaban en las generaciones anteriores, hoy no sirven para interpretar las experiencias de sexualidad juvenil. Por un lado, hacen crisis las formas habituales de pareja, ya no sólo el matrimonio, sino incluso el "pololeo", dando paso a la ocasionalidad como la manera cotidiana de vivir la sexualidad (la 
figura del "ponceo"). Sin embargo, esto deja a la sexualidad juvenil con un problema de validación. La pareja sigue siendo el contexto ideal para la sexualidad deseada, sin embargo, las formas conocidas de ésta ya no convencen a las nuevas generaciones, que no temen a experiencias que no comporten un proyecto de pareja.

Actualmente, la sexualidad ya no se regula, por lo menos totalmente, ni por el amor ni por la conquista, así como también se aleja de las instituciones tradicionales, incluso las más recientes. Esto significa que cae el nexo social de la sexualidad, quedando "desconectada de la subjetividad que la experimenta" (Canales, 1994). Cabe entonces hacerse la pregunta, una vez caída la legitimación del "amor", por cuáles son ahora los motivos que cubren el deseo y la experiencia del placer. Ocurre que el sexo ya no está al servicio ni de un proyecto ni de un sentimiento, con lo que se transforma en un transgresor que no conoce sus límites. Hoy la discusión ya no es por las relaciones sexuales pre-matrimoniales ni por la legitimidad de la pareja sexual única, sino que se mueve en torno a las motivaciones profundas para embarcarse en una relación sexual.

Ante la crisis de las instituciones y los relatos legitimadores, la sexualidad aparece como un problema a interpretar, un tema pendiente. Se inicia así la búsqueda de una nueva semántica que regule y fije el sentido de la sexualidad. Aún no cristalizan nuevas interpretaciones que hagan de la vivencia sexual una experiencia "normal" (en su sentido sociológico), lo que va generando situaciones de miedo, inseguridad y duda, pues la "verdad" ya no aparece tan patente. No se conforma un nuevo discurso sobre la sexualidad que reemplace al tradicional, por lo que domina la ambivalencia.

Nos encontramos hoy con una ausencia de modelos que tengan la capacidad de otorgar sentido a la vivencia de la sexualidad. Aparecen nuevas vivencias que no están cubiertas por los discursos antiguos, lo que va produciendo una tendencia a la cri- 
Nuevas Formas de Moralidda en los y las Jóvenes chilenos. Estudio exploratorio sobre configuraciones valóricas emergentes en jóvenes estudiantes de Santiago

sis de los modelos tradicionales en ausencia de otros nuevos. La ocasionalidad se transforma en el paradigma complicado de la nueva sexualidad (Ibid). El pololeo ciertamente aún existe, pero la experiencia límite se va trasladando cada vez más hacia una nueva frontera, el sexo fuera de la pareja estable, y es en estas formas de sexualidad donde se proyecta el lugar crítico de la cuestión. Es ahí donde el sexo es puesto en observación: entre la libertad y el sentido de su liberación.

\section{El dilema moral juvenil: ¿Qué hacer con la libertad?}

La búsqueda de nuevos límites que se expresan en las prácticas del carrete y el sexo, así como el problema de la incertidumbre en el plano sexual y su consecuente sentimiento de vacío, tienen un carácter eminentemente moral y, por ende, la dimensión ética pasa a ocupar un lugar constitutivo en la construcción del concepto de sexualidad. Sin embargo, hemos planteado ya que el ámbito de la ética, como referente de un código normativo, se encuentra hoy en una situación crítica.

En las conversaciones juveniles respecto del carrete y la sexualidad comienza a aparecer marcadamente la pregunta por la cuestión del límite. Esto, porque ellos son la primera generación que se plantea el problema de la moral post-tabú. En cierta forma, la liberación ya no es demanda, ahora se vive. Le pregunta es entonces: dónde están los límites. Para Canales (1994), frente a ella se desarrolla el dilema entre dos opciones: la responsabilidad o la disipación. En la actualidad la pregunta moral ha sido reemplazada por una de carácter ético. En el caso del sexo, por ejemplo, una sexualidad ética es aquella en la que el sujeto tiene la capacidad de responder por sus actos, ante sí mismo y ante quienes estime pertinente; su contraparte es una sexualidad emborrachada o carretera, en donde el sujeto se pierde, enmudece, y no es capaz ya de dar cuenta de sus actos. Así lo mismo con el carrete en general.

El tema es que la cuestión ya no está referida a un patrón de buena sexualidad. No se busca una nueva moral que revele los 
límites por norma, sino que se desarrolla más bien una distinción ético-práctica: "respóndete a ti mismo" o, también, "cuídate". Es un tema no de disciplina, sino de reflexividad.

¿Cómo lo hace el sujeto frente a la crisis de la moralidad tradicional? En este sentido, podríamos decir que las juventudes hoy deben hacer un recorrido que nadie ha hecho antes, en tanto se experimentan circunstancias para las que no hay disponibles interpretaciones previas. Deben, entonces, construir sus propios recursos interpretativos. Es el tema de la constitución del sujeto moral cuando la tradición ya no lo logra, cuando no está garantizada su eficacia normativa.

El problema no es menor, porque estamos hablando de una elaboración filosófica -un saber vivir- de la cuestión moral como un discurso para hacerse cargo de la libertad. Esta última entendida como libertad respecto de la moral (la tradición, el colectivo, la norma). La formulación juvenil respecto de aquello podría verbalizarse en un "saber lo que estás haciendo". No habiendo nada que conocer (o nada que observar, en su sentido normativo), pareciera que el sujeto regresa a conocerse a sí mismo: "si nadie te orienta, oriéntate a ti mismo". La pregunta es por el sujeto, donde antes era por la norma. Lo que está en juego aquí es la propia condición de sujeto: el que sabe lo que hace, que puede revivir ese sentido sin contradicción, o pagando los costos cuando no lo logra. Es reconocerse o negarse en la acción. Ya no es distinguir el bien y el mal, sino "lo que te haces bien y lo que te haces mal".

La cuestión es entonces comprender cómo se desarrolla esa doble tendencia frente a la crisis normativa. Por un lado, el "encanallamiento", el mal valor del exceso, en que la subjetividad se retrae, la disipación, el "reviente" o desborde; y, por el otro, la reflexión indagatoria, en que el sujeto juvenil tiende a hacerse cargo de la ausencia de la norma y busca construir por sí mismo nuevos límites, al no encontrar respuestas legítimas en el mundo adulto. En esta última rigen criterios prácticos más que morales, pues se suspende el juicio sobre la moralidad, es decir, no se 
aprueba ni rechaza, sino que levanta un criterio de responsabilidad que busca impedir efectos indeseados. Una vez caída la norma, queda la libertad, y es ésta la solución en que los y las jóvenes viven. El problema es cómo hacerse cargo de esa libertad, cómo gobernarla y no ser disipado por ella.

\section{El discurso juvenil respecto a la crisis normativa}

Ya hemos puesto en perspectiva el fenómeno en estudio. Veamos ahora cómo se articula en la conversación juvenil el problema de la cuestión moral, es decir, cómo se representan ellos mismos la crisis normativa de la que hemos estado hablando.

El análisis de las discusiones se articuló en base a cuatro hilos discursivos o ejes temáticos. El primero, referido a los valores en general, en el que se identificó la particular manera en que se entiende el valor desde las juventudes, y también qué se entiende por él, es decir, qué se dice cuando se dice "valor" y, también, cuáles son los principales valores ensalzados por los y las jóvenes. En segundo término, se buscó comprender cómo ellos y ellas entienden el fenómeno de la libertad, en torno a la cuestión del límite como pregunta esencial. Frente a ello, se identificaron dos posibles respuestas. Por un lado, la noción de la disipación, expresada en los ámbitos del carrete y la sexualidad, como una especial situación de amenaza para el cultivo de la propia subjetividad. Como contraparte, la emergencia de una nueva configuración valórica, basada en una ética de la responsabilidad y el autocontrol, como construcción de un camino que permite a las y los jóvenes mantener su autonomía como sujetos, en el marco de la desarticulación entre ética y moral.

\section{Los valores}

Lo primero a destacar son las nociones transversales en el seguimiento de la discusión de los grupos. Por un lado, se plantea una cierta desconfianza hacia el orden social presente, que se articula 
como una crítica de la sociedad contemporánea respecto de su situación moral. Por el otro, y de acuerdo a esto, aparece un marcado sentimiento de búsqueda juvenil por la cuestión del sentido. Esto se expresa a partir de la idea de carencia o vacío.

En las discusiones se identificaron dos sensibilidades básicas y discrepantes en torno a la actual situación de los valores. Una de ellas se expresa como un sentimiento de pérdida de un mundo organizado desde la moral, que implicaría la progresiva desaparición de los valores, y también de ideales, especialmente en la juventud. Se señala que los antiguos referentes morales hoy fallan en su capacidad de funcionar como tales. Frente a esto, se plantea la idea de un retorno a los valores tradicionales, es decir, a las viejas fuentes de significación, especialmente la familia como el principal reducto moral.

Por contrapartida, es posible apreciar la emergencia de una nueva mirada juvenil respecto de los valores. Esta se establece como un discurso que no mira con rechazo las transformaciones contemporáneas, y se levanta como una perspectiva de elogio del pluralismo y la tolerancia. Dicha perspectiva juvenil no asume como propio el discurso referido a "lo inmoral". Es decir, el valor no se ha perdido, sino que simplemente hoy existe una diversidad de configuraciones valóricas. Ahora, ello supone, de todas formas, una crisis de normatividad, en tanto se diversifican las posturas respecto del fenómeno moral, y ya no es fácil saber cuál de ellas es la que se debe seguir. Enfrentados a esta situación, estos y estas jóvenes articulan una solución eminentemente pragmática, en la que se entiende que ya no existen prescripciones morales omniabarcadoras, por lo que se hace necesario que cada sujeto vaya elaborando una solución propia, siempre autorreferida y sin pretensiones de universalidad. Es decir, desde aquí lo que se valora es la capacidad de cada joven para abrir nuevos caminos. Surge así un discurso que releva el papel de la tolerancia, entendida como la aceptación de las diferencias, sin valoraciones morales, y un aprender a respetar las decisiones del otro y ser empático con ellas. 
Nuevas Formas de Moralidda en los y las Jóvenes chilenos. Estudio exploratorio sobre configuraciones valóricas emergentes en jóvenes estudiantes de Santiago

La idea de "crisis" valórica es interpretada más bien como una crisis de sentido. Es decir, un mundo donde no existen valores compartidos que determinen las acciones en una dirección única aplicable a las distintas esferas de la vida cotidiana. Surge así la concepción de que la adhesión valórica corresponde a un fenómeno eminentemente personal, y sometido a constantes transformaciones. Cada uno cultiva aquello que le parece bueno, es decir, a cada quien su propio valor o, más aún, su propio bien. Esto implica que el sistema subjetivo de significación última y el modelo recibido durante la infancia se va complejizando en su nivel de coherencia, por una distribución social más heterogénea de la visión de mundo. La tradición ahora aparece como múltiple, por lo que su eficacia normativa ya no está garantizada. Esto significa que los y las jóvenes se vean obligados a conformar sus propios caminos. Las acciones pueden ser correctas en un sentido y equivocadas en otro, ya que el comportamiento "correcto" se encuentra sujeto a múltiples criterios de evaluación. Los espacios de sociabilidad y asociatividad son vistos desde una perspectiva de libre adhesión, por lo que el individuo tomará de ellos lo que mejor le parezca. El camino a la adultez aparece como un proceso de toma de decisiones de acuerdo a valoraciones personales, por sobre el respeto a normas sociales. Estos y estas jóvenes reclaman, así, su autonomía en materia moral, entendida como un respeto a la libertad de decisión a este respecto.

Con todo, la adhesión valórica aparece siempre como libre, y la transgresión, por ende, es permanente. No es fácil determinar un principio claro y univalente respecto de cada situación particular, por lo que a cada una de ellas corresponden distintas apreciaciones morales y, con ellas, distintas configuraciones valóricas. Al circular una diversidad de discursos respecto de lo bueno y lo malo, así como de lo correcto e incorrecto, el desarrollo de la conciencia moral queda relegado a la particular experiencia de vida del sujeto. Las instituciones sociales aparecen con una capacidad normativa restringida, con lo que el individuo se ve cada vez más libre en su accionar. Todo se puede elegir, incluso 
los particulares "significados últimos", es decir, los valores. La cultura pierde progresivamente su carácter coercitivo, y es vista, más bien, como una mezcla de distintas posibilidades, accesibles en principio. El desafío es, entonces, comprender qué se entiende por valor en las distintas esferas sociales, dada la multiplicidad de discursos morales.

Surge así, un discurso que promueve nuevos valores, o por lo menos una nueva comprensión de ellos. El valor principal, y mínimo exigido, es el respeto, que aparece como la base de un orden social deseable. En el ámbito social, emerge entre las y los jóvenes la concepción de un desgaste en la calidad de los vínculos, y entonces el respeto aparece como la tolerancia. Sin ese respeto, el orden social caería en el individualismo y el relativismo, manifestados como la vivencia sin valor de la diversidad. Cuando no hay consenso en materia moral, lo que queda es mantener el buen vínculo social. Acorde con esto, la etapa de la juventud es entendida como un camino que, precisamente, implica el encuentro con la diversidad, y la generación del valor de un buen convivir. Las decisiones del otro no pueden ser catalogadas de buenas o malas, pero esto hace necesario un desarrollo de la capacidad empática. Lo importante es respetar dichas decisiones, siempre y cuando se garantice el derecho mutuo a la libertad. El orden social desde la tolerancia es entendido por estas juventudes como un "no hacer daño al otro". El respeto aparece como el mínimo exigido para la convivencia, el peligro surge, entonces, como la obstaculización de la libertad del Otro. Ahora, el respeto lo es del otro, pero también lo es de sí mismo.

El respeto de sí corresponde al valor como juicio, contención, criterio y/o límite. El valor así entendido, funciona como delimitador de un camino que permite vivir en la intemperie moral. Es discernir entre "lo que te haces bien y lo que te haces mal", que ya no de lo bueno y lo malo, a partir de un sentido práctico. El desarrollo como sujeto implica generar dicha capacidad de distinguir, es decir, el criterio y el buen juicio. Se reprueba la falta de 
Nuevas Formas de Moralidda en los y las Jóvenes chilenos. Estudio exploratorio sobre configuraciones valóricas emergentes en jóvenes estudiantes de Santiago

respeto por sí mismo, entendida como la carencia de un rumbo claro en la vida, y ya no como tomar el "mal camino". Es decir, no se habla de una juventud "descarriada", sino de una juventud "perdida", sin una vía que conforme su propia subjetividad. Respetarse como sujeto implica tener una conciencia y consideración que den lugar a la capacidad reflexiva de dar cuenta por los propios actos. El valor permite el desarrollo de la propia subjetividad, evitando las consecuencias no deseadas de la libertad vivida como desborde.

\section{La libertad}

Los y las jóvenes manifiestan que la sociedad contemporánea no tiene la capacidad de generar normas potentes que liguen al individuo con un orden determinado. Es decir, se vive una marcada libertad en materia moral, que por un lado puede vivirse como una situación amenazante, pero, por otro, como posibilitadora de la emergencia de un sentido de autonomía responsable en el sujeto.

La libertad vista como crisis se plantea, en primer lugar, como una excesiva permisividad por parte de la familia. Esto implica que los y las jóvenes no sepan dónde encontrar el sentido, y entonces se hace un llamado al retorno de las formas tradicionales de educación. La libertad terminaría deformándose, para devenir en libertinaje o desenfreno: sin límite ni contención y, finalmente, sin valor. Ahí surge la amenaza, articulándose un discurso temeroso de la anomia que hace una demanda por el orden tradicional. La apertura normativa es vista como caos social. En la actualidad no existirían caminos ya probados que garanticen estar en lo correcto; se deslegitiman todas las autoridades morales, por lo tanto sólo quedaría una opción: el retorno.

Por contrapartida, la libertad es vista, desde el otro discurso, como una oportunidad, y el tema está en aprender a manejarla. En ella se busca un intento de solución de cara al nuevo contexto, que corresponde a la formación, por parte de cada joven, 
de un camino propio que permita gobernar la libertad. En general, entonces, se hace una valoración positiva de la libertad en tanto construcción humana, y también de la nueva constitución familiar basada en el diálogo y la simetría. Sin embargo, surgen también sentimientos de desmotivación y soledad, dado que al no haber más normas que transgredir, se va perdiendo el sentido mismo de esa liberación. Esto implica, a su vez, que vaya apareciendo una renovada concepción de la familia, como un espacio que permite ir aprendiendo a manejar la libertad desde la infancia, dando lugar al surgimiento de la responsabilidad, pero ahora desde la autonomía.

Ahora, frente a la crisis de normatividad, surgen, para las y los jóvenes, dos caminos posibles: la entrega total del individuo a la crisis, es decir, su disipación, o la conformación de una nueva manera de enfrentar la cuestión moral desde la libertad, ahora a partir del sujeto enfrentado a los resultados de su propio obrar.

\section{Disipación}

La disipación surge como un riesgo permanente para las juventudes, manifestada básicamente en los ámbitos de la fiesta -carrete- $\mathrm{y}$ en la sexualidad.

En general, el carrete es referido como desenfreno, es decir, un lugar donde la normatividad es relativa y cuyo ámbito precisamente invita a la transgresión. El carrete en tanto disipación, unido al consumo de sustancias psicoactivas, es visto como pérdida del centro. Así, el problema no está en la práctica misma del carrete, sino en que ésta tenga que llenar un vacío de sentido. No es "lo malo" tenido por "bueno", sino que lo que realmente preocupa es la desaparición de toda noción de límite: el carrete como camino sin dirección, por contraposición a instancias como el estudio, el trabajo y la familia. Sin valor, no hay respeto de sí, por lo que el riesgo es ir más allá de la instancia puntual festiva, perdiendo la posibilidad de mantener expectativas en el futuro. Esto significaría abandonar el proyecto de vida, lo que implica 
Nuevas Formas de Moralidda en los y las Jóvenes chilenos. Estudio exploratorio sobre configuraciones valóricas emergentes en jóvenes estudiantes de Santiago

la crisis profundizada en el sujeto. Aparece la figura del "perdido" y el "borrado", como quien no puede dar cuenta de su accionar y, por ende, pierde su calidad de sujeto propiamente tal. La transgresión no es el problema, sino el carecer de un anclaje que otorgue significación o proyección. La libertad es ordenada así entre la prudencia, el buen valor de lo libre, y la desmesura, el mal valor del exceso, cuando la subjetividad es sobrepasada por la práctica del carrete-consumo.

En el caso de la sexualidad, también aparece el miedo de su entrega a la anomia, salida más allá de la privacidad y desatada de los antiguos valores de amor, virginidad y pareja estable. Sin embargo, aparece también la voz tolerante, abierta a la diversidad de prácticas sexuales. Hoy, la sexualidad es vista como tematizada -no se esconde- y liberada -no se reprime-. Además se aprecia una mayor apertura a la experimentación. Se amplía el rango de normalidad: el sexo tal cual, sin buscar "apellidos" (sexo marital o con amor) que denoten su carácter moral. Aquí aparece con fuerza la idea de respeto como valor mínimo. De todas formas, también el riesgo es a la disipación: el sexo anónimo, orgiástico, desapegado. Como contrapartida se releva el sexo respetuoso, digno, que da sentido de sí, como la posibilidad de una sexualidad deseable. Sin responsabilidad no hay goce, pues el individuo no se reconoce, no es sujeto. Se reprueba, entonces, lo absurdo de transgredirse a sí mismo. Aparece la sensatez como un no exponerse al exceso, como mantenerse entre la libertad y autonomía, el sujeto como tal, y evitar su pérdida: la disipación. El tema pasa a ser, entonces, la prevención, y no el pecado como lo contrario a la virtud. El sexo como vivencia sin sentido no contribuye a la conformación de una relación estable que contribuya, como soporte afectivo, a la realización del proyecto biográfico. Precisamente, la sexualidad hoy estaría liberada de las instituciones típicas, pero sin instituciones nuevas definitivas, con lo que la experiencia sexual queda en un déficit de significación y sentido. Esto implica que se reconoce la autonomía individual, pero aún hay cierta reprobación: la ocasionalidad se critica como falta de 
valoración propia y auto-respeto. Ahora, como resulta dificultoso generar una nueva estructura de sentido, los y las jóvenes rescatan la necesidad de tener, por lo menos, una preocupación por las consecuencias.

\section{Responsabilidad y autocontrol}

De acuerdo a lo anterior, es posible ver cómo se va desarrollando en las y los jóvenes un discurso reflexivo, en el que se postula que, estando todo permitido, la única opción es el autocuidado. Es decir, tener un sentido de responsabilidad, que funcione como un criterio que permita impedir efectos indeseados.

Con respecto al carrete, esto surge como capacidad de autocontrol, es decir, un saber cuidarse. Lo problemático no es el consumo-carrete en sí mismo, sino la pérdida de vigilancia sobre sí. Aprender a autocontrolar-se, nace de la experiencia misma del carrete, y que éste no se vaya de las manos. Traspasando los límites se va aprendiendo y madurando. Se articula, entonces, un doble aprendizaje: autoconocimiento -qué te sucede- y autocontrol -cuánto puedes-. De esta forma se reconstruyen los límites, pero ahora autorreferidos. La responsabilidad sirve, entonces, para ir fijando los límites y, con ellos, el sentido. No implica negar la experiencia, sino mantenerla en los márgenes de la re-creación (y todo lo que ello implica: el ocio como espacio constructivo). El sujeto va adhiriendo a prácticas legitimadas en la responsabilidad, con lo que la demanda por un orden al cual plegarse va dando lugar a una verdadera cultura del autocuidado, es decir, un cuidado de sí mismo o mutuo cuidado.

En el marco de la sexualidad, la responsabilidad es vista como la posibilidad de responder aun cuando los resultados no son los previstos. Ser responsable significa tomar el mejor camino para uno, esto es, tener uno claro y no actuar desde la disipación: no perderse. Este camino se elige libremente y no está marcado ya por un juicio moral heterónomo, esto es, no está necesariamente legitimado por el colectivo, sino desde la individualidad. Esto 
Nuevas Formas de Moralidda en los y las Jóvenes chilenos. Estudio exploratorio sobre configuraciones valóricas emergentes en jóvenes estudiantes de Santiago

implica no referirse ya a lo que el orden social establece como bueno o malo para todos, sino, más bien, el sujeto enfrentado a los efectos de su propio obrar. Lo otro es transgredirse a sí mismo: la estupidez.

\section{Hacia una cultura del autocuidado}

A partir de este estudio es posible constatar que hay dos sentimientos muy marcados en las juventudes chilenas. Uno referido al orden intersubjetivo, que se expresa como un profundo juicio crítico de nuestra sociedad, y el otro relacionado con la propia subjetividad: la de búsqueda de sentido. Ambos están vinculados a un principio ético que busca la autorrealización, y apuntan hacia lo mismo: que hoy no están claramente establecidos -o incluso también negados- los caminos que permitirían su desarrollo.

Ahora bien, hemos señalado que los y las jóvenes conforman mundos diversos y heterogéneos, en que se dan novedosas articulaciones de sentido entre lo viejo y lo nuevo. De esta forma, nuestro estudio nos permitió identificar dos aproximaciones juveniles básicas y discrepantes respecto a la cuestión de la situación moral en la sociedad contemporánea. Una que habla desde el concepto tradicional del valor y la idea de su desaparición, expresada como un sentimiento de la pérdida de un mundo organizado moralmente. Esto aparecería aún más marcadamente en la visión de una juventud que ya no demuestra valor alguno. Además, se lamenta la incapacidad de los antiguos referentes morales en su capacidad de funcionar como tales. Frente a ello, se postula la necesidad de un retorno a los valores tradicionales y a las viejas fuentes de significación. Entendemos que este discurso constituye un repliegue frente a la libertad, como un cobijarse en reglas sólidas que permitan saber-se en lo correcto.

Sin embargo, como hemos señalado ya, la ambigüedad está instalada en los discursos juveniles. En tanto aparece, por un lado, la búsqueda de alguna forma de autoridad que les señale dónde está el camino, pero, a la vez, una incomodidad cuando 
ello se manifiesta como obligación. Se busca la libertad respecto de la tradición, pero, también se buscan nuevos criterios interpretativos en la asignación de sentido.

Así, es posible apreciar la emergencia de una nueva ética de la intersubjetividad, basada en los valores de la tolerancia y el pluralismo. Desde ella no se mira con rechazo la nueva situación moral. Por el contrario, se manifiesta como una perspectiva de elogio de la nueva diversidad.

Esta segunda perspectiva no está marcada por la sensación de pérdida de los valores, sino que, más bien, reprocha la falta de oportunidades que la sociedad ofrece a los y las jóvenes para articularse como actores empoderados de su propio devenir. Se plantea también como una crítica de la forma tradicional de familia, en tanto ente represor, y del conservadurismo en general.

Ahora, en ambas perspectivas juveniles es patente el sentido de una crisis de normatividad, en tanto la elección por lo correcto estaría muy dificultada por la diversificación de las normas. Sin embargo, frente a dicha situación, la segunda mirada permite a los y las jóvenes articular una solución eminentemente pragmática, en la que se acepta que ya no existan prescripciones morales omniabarcadoras, lo que hace necesario que cada sujeto vaya elaborando una solución propia, siempre autorreferida y sin pretensiones de universalidad. Surge así la relevancia fundamental del proyecto de vida, como camino construido por el sujeto para su realización personal. Esto implica también el respeto mutuo para la realización efectiva de los proyectos biográficos de todos.

Ahora bien, ¿qué entienden los y las jóvenes por valor? A partir de los resultados de nuestro estudio es posible señalar que el valor es entendido en una doble dimensión. En su aspecto social, corresponde al establecimiento de una mínima calidad de los vínculos sociales, que puede resumirse en base al respeto de las libertades mutuas, lo que garantiza la autonomía de cada sujeto como tal. Se trata, al fin y al cabo, de un nuevo régimen social basado en la individualidad, y ya no desde la lógica comunita- 
Nuevas Formas de Moralidda en los y las Jóvenes chilenos. Estudio exploratorio sobre configuraciones valóricas emergentes en jóvenes estudiantes de Santiago

ria, que funciona en tanto se garantice la autonomía de todas y todos.

En su aspecto individual, el valor se refiere a la capacidad subjetiva de generar los propios límites. Se entiende dicha capacidad como la condición fundamental del sujeto como tal: el reconocerse en las propias acciones, y mantener una autonomía sin ser disipado por el nuevo contexto de libertad. El auto-respeto como contención resulta en la protección del sujeto mismo. Es la conformación de una moralidad autónoma, en que el valor permite el desarrollo de la propia subjetividad.

La configuración valórica emergente en las juventudes podría ser llamada "autonomista", en tanto su problematización respecto de la cuestión de los límites y la apertura de nuevos espacios de libertad adquiere dicho sentido. Es un discurso que promueve la autonomía subjetiva en un mundo desnormativizado, que le permite al sujeto seguir viviendo en base a la consecución de un principio de realización personal, poniendo como mínimo deseable el respeto por la libertad mutua. Es así como hemos visto que se desarrollan los ámbitos de la sexualidad y el carrete. Frente a la falta de regulaciones potentes y univalentes, la construcción de normas novedosas de carácter relativo y funcional a la situación, o el repliegue a las viejas tradiciones. Ambas constituyen respuestas juveniles posibles, que evitan la pérdida del sujeto, pues sin temor normativo ni cautela reflexiva, el riesgo sería inconmensurado por las y los jóvenes en sus prácticas recreativas, dando lugar a una subjetividad "embriagada" que corresponde al fin de la autonomía. Así, lo que se sanciona socialmente, por parte de las juventudes, es el vivir en el exceso.

De esta manera, aparece en las y los jóvenes un discurso reflexivo, en el que se postula que, estando todo permitido, la única opción es el autocuidado. Es decir, tener un sentido de responsabilidad, que funcione como un criterio que permita impedir efectos indeseados. No se trata de una configuración valórica cristalizada de una vez, sino que obedece, más bien, al principio de la 
necesidad de construir caminos propios y respetarlos, como la única posibilidad de vivir en la intemperie moral.

El autocuidado corresponde, por un lado, a la capacidad de autocontrol, es decir, un saber cuidarse. Lo problemático no es una práctica contra-norma determinada, sino la pérdida de vigilancia sobre sí. Este aprender a autocontrolar-se, nace de la experiencia misma juvenil, sobre todo en los escenarios del carrete y la sexualidad. Traspasando los límites se va aprendiendo y madurando, dándose la posibilidad de una reconstrucción normativa, pero ahora autorreferida. El sujeto se hace cargo de la ausencia de normas y conforma él mismo sus propios límites, a partir de una responsabilidad que permite irlos fijando, para dar lugar, con ellos, al sentido. No implica negar la experiencia, sino mantenerla en los márgenes de la re-creación y del ocio como espacio constructivo en su sentido ritual. El sujeto va adhiriendo a prácticas legitimadas en la responsabilidad, que en algunos casos llegan a generar una verdadera cultura del autocuidado. En ésta, la recreación festiva es permitida y, más aún, fomentada, pero se comienza a vivir desde la prevención.

El autocuidado también puede entenderse como responsabilidad, en tanto posibilidad de responder por lo acontecido, aun cuando los resultados no son los previstos. En ese sentido, es la capacidad de tomar buenas decisiones. Es la cuestión moral mirada desde la configuración valórica personal, que conforma un proyecto biográfico en base a la autorrealización. Ser responsable significa tomar el mejor camino para uno. Lo otro es la disipación del sujeto.

En este sentido, el principal preventor de riesgos es tener un proyecto de vida claro y plegarse a él. Dicho camino no se conforma ya a partir de juicio moral heterónomo, sino que encuentra su sustento en la subjetividad. Esto significa asumirse como sujeto, enfrentado en soledad normativa a los resultados de sus acciones. 
Nuevas Formas de Moralidda en los y las Jóvenes chilenos. Estudio exploratorio sobre configuraciones valóricas emergentes en jóvenes estudiantes de Santiago

No hay pregunta por la norma, sino por el sujeto mismo: la responsabilidad y el autocontrol permiten la propia conservación. Así, el peor resultado es aquel que implica perder el propio respeto, lo que significa entorpecer las mismas metas del sujeto. De esta forma, aparece el autocuidado como la solución juvenil que permite gobernar la libertad, sin ser disipado por ella. Como un principio no moral, pero sí marcadamente ético, que permite la configuración de una autonomía en las conformaciones valóricas juveniles, conjurando el riesgo de la desubjetivación y la pérdida total de sentido.

\section{Bibliografía}

Bauman, Zygmunt (2004): Ética posmoderna. Buenos Aires: Siglo XXI.

Berger, Peter y Thomas Luckmann (1996): “Modernidad, pluralismo y crisis de sentido", en Estudios Públicos No 63 (invierno 1996), Santiago de Chile.

Canales, Manuel (1994): El discurso sobre sexualidad entre estudiantes de educación superior, clase media-baja. Santiago de Chile: CORSAPS.

Duarte, Claudio, S. Bustos, F. Ramírez e I. Quezada (2004): Juventudes de Chile. Santiago de Chile: LOM Ediciones.

Garretón, Manuel Antonio (2000): La sociedad en que vivi(re)mos. Santiago de Chile: LOM Ediciones.

INJUV (2006): Segundo Informe Nacional de Juventud. Santiago de Chile.

Matus, Christian (2005): “El carrete como escenario. Una aproximación etnográfica a los códigos de la sexualidad ocasional en jóvenes urbanos", en Última Década, año $13, \mathrm{~N}^{\circ} 22$, agosto 2005. Valparaíso: CIDPA.

Parker, Cristián (2000): Los jóvenes chilenos: cambios culturales; perspectivas para el siglo XXI. Santiago de Chile: Unidad de Estudios Prospectivos, MIDEPLAN.

PNUD-INJUV (2003): Transformaciones culturales e identidad juvenil en Chile. Santiago de Chile.

Villela, Hugo, I. Palma, y M. Canales (1998): Prevención de embarazo adolescente: una mirada desde el Estado. Santiago de Chile: SERNAM. 